\title{
Assessment of the warfarin anticoagulation knowledge of patients with mechanical mitral valve prosthesis and its effect on therapy adherence and relevant complications
}

\author{
İKER KAYA ${ }^{1, \text { A, в, D, e }, ~ A L I ~ E K R E M ~ K O ̈ N E R ~}{ }^{2, ~ в, ~ c, ~ ғ ~}$ \\ ORCID ID: 0000-0002-7038-7816 ORCID ID: 0000-0002-7038-7816 \\ ${ }^{1}$ Department of Cardiovascular Surgery, Tokat State Hospital, Tokat, Turkey \\ 2 Department of Cardiovascular Surgery, Gaziosmanpasa University, Tokat, Turkey
}

A - Study Design, B - Data Collection, C - Statistical Analysis, D - Data Interpretation, E - Manuscript Preparation, F - Literature Search, G - Funds Collection

Summary Background. The mechanical valves that are commonly used in replacement surgery pose risks of thromboembolic events. Thus, anticoagulation after surgery is essential. Warfarin is a widely used anticoagulant with a narrow therapeutic index and major side effects. This study aimed to assess the warfarin knowledge of patients with mechanical mitral valves and its effect on adherence and complications.

Objectives. This study aimed to assess the warfarin knowledge of patients with mechanical mitral valves and its effect on adherence and complications.

Material and methods. This cross-sectional study was conducted on a group of 168 patients, with a mean age of $61.76 \pm 9.35$ years, predominantly consisting of females. The patients were visited at their homes and interviewed directly using a self-developed questionnaire that assessed the profile and knowledge of the patients on warfarin anticoagulation and relevant side effects.

Results. The results demonstrated a poor level of knowledge among the patients, although they received medical information. The statistical analyses revealed a significant association between the medical knowledge provided and increased international normalised ratio (INR) knowledge and adherence to prescriptions and follow-ups. The rates of complications were found to be significantly higher in patients who did not have knowledge about INR and who did not adhere to follow-up visits.

Conclusions. We identified a critical gap in the knowledge of patients about warfarin therapy. The significant association between the lower rates of complications and medical knowledge is promising. We suggest that the current study be extended onto larger and more focused research to develop standardised tools to educate patients on anticoagulation.

Key words: warfarin, patients, knowledge, treatment adherence and compliance.

Kaya I, Köner AE. Assessment of the warfarin anticoagulation knowledge of patients with mechanical mitral valve prosthesis and its effect on therapy adherence and relevant complications. Fam Med Prim Care Rev 2021; 23(2): 174-178, doi: https://doi.org/10.5114/ fmpcr.2021.105919.

\section{Background}

Valvular heart disease is a growing clinical problem associated with high morbidity and mortality in the elderly population [1]. The preferred treatment modality is the replacement of the impaired valve with a prosthesis. Surgery can be performed using a biological or mechanical valve. Although mechanical valves have longer durability, their risk of thrombogenicity is higher than that of biological valves [2]. Therefore, lifelong anticoagulation with vitamin $\mathrm{K}$ antagonists has been the standard for medical care after mechanical valve replacement surgery [3]. Warfarin is a widely used vitamin $\mathrm{K}$ antagonist, with a narrow therapeutic index, extensive dosage variability and major side effects. Whereas dosage insufficiency restricts its action on thromboprophylaxis, overdosage can lead to life-threatening bleeding [4]. The interactions of warfarin with certain foods, drugs and supplements can cause improper dosage [5]. Thus, the education and close monitoring of patients using warfarin are of utmost importance. The standard procedure for evaluating anticoagulation measures the international normalised ratio (INR) [6]. The European Society of Cardiology endorsed self-monitoring by measuring the INR of patients who had been sufficiently educated and could be controlled for procedural quality [2]. Recently, patient education and adherence to warfarin therapy have been addressed in a guideline by the American
Society of Hematology. An evidence-based approach and patient education are required to recognise anticoagulant risks [7].

Medical literature has extensively assessed the adherence, satisfaction and quality of life of patients under warfarin anticoagulation $[3,8,9]$. Adherence to a drug is the degree of a person's behaviour that matches the recommendations of the physician, i.e. using the medications as prescribed, modifying his/ /her diet and changing his/her lifestyle. The safety of patients using warfarin is as vital as therapeutic success, which is highly dependent on the adherence and proper education of patients. In addition to the drug regimen, INR monitoring, dietary factors containing vitamin $\mathrm{K}$ and timely recognition of relevant complication signs should be included in the adherence assessment of warfarin anticoagulation therapy [10]. The rate of complications has been shown to decrease with the better control of anticoagulation linked to the knowledge of the patient $[9,11]$. A comprehendible tone in communication must be used for the delivery of medical information for its effective application to therapy [12]. To minimize complications, patients who had valve replacement surgery should be encouraged and further educated about doing their own self-assessment. Therapy quality and patient satisfaction can be improved by identifying and addressing informative deficiencies. Thus, the present knowledge of patients should be evaluated as a first step in improving the quality of anticoagulation therapy and patient care [13]. 
This study assessed the knowledge profiles of patients under warfarin anticoagulation for mechanical mitral valve replacement surgery and evaluated the relationship between knowledge and anticoagulation-related complications.

\section{Material and methods}

\section{Study group}

We established the patient group in this descriptive and cross-sectional study by scanning the archives of all city hospitals as well as our outpatient clinics to include the maximum number of cases (those at least 18 years old, had mechanical mitral valve replacement surgery and were under warfarin anticoagulation). Patients were excluded from the study if their medical notes showed anticoagulant therapy with non-warfarin drugs or indications other than mechanical mitral valve replacement.

Out of the initially identified 226 patients who met the study criteria, 170 patients who were contacted by phone or home visit gave their informed consent to participate in the study. Either the patient or a first-degree relative who knew about the surgery was directly interviewed face-to-face at their homes. Two patients were lost during the study, and their data was excluded from the results. The institutional ethics committee approval was obtained before the start of the study.

\section{Study method}

As the previously published questionnaires in studies similar to ours were not applicable to the current study design, and partly due to the language barriers of the participants, a self-developed questionnaire was used in the assessment. The respondents' answers to the verbally directed questions were immediately recorded. When the need arose or when a request was made to repeat the question(s), more comprehendible explanations were provided to the participants. When the response given to a particular question did not correspond to the record on the medical file, the latter information gathered directly from the participant during the study was included in the study data.

The questionnaire consisted of four sections comprising mostly of dichotomous response (yes/no) questions. Data on demographics, such as age, gender and education, was collected in the first section. The second and third sections provided data on the surgery and warfarin anticoagulation as follows: the date of operation, medical history, indication of surgery, the medical features of perioperative period, rationale of warfarin use, adherence to prescription (dose and timing) and follow-up visits, levels of INR, food interactions of warfarin, warfarin recognition among other prescriptions, regularity of warfarin use, risks associated with incorrect dosage and any cessation of warfarin use (either by physicians' recommendation or self-decision).

The final section was developed for warfarin-related complications, such as post-op stroke and bleeding (gingival, gastric, blood in urine, meno/metrorrhagia and easy bruising). The participants were also questioned about their attitudes when complications occurred.

\section{Statistical analysis}

The descriptive statistics for the continuous variables were presented as the mean \pm standard deviation, and median and minimum-maximum values were provided when required. The categorical variables were presented as the number and percentage and compared using the chi-square or Fisher's exact test. The statistical analyses were performed using SPSS 17.0
(SPSS Inc., Chicago, IL, USA). A p-value less than 0.05 was considered significant.

\section{Results}

The study was conducted on 89 female $(53 \%)$ and 79 male (47\%) patients $18-83$ years of age, with a mean value of 61.76 \pm 9.35 years. Three-quarters of the patients $(n=126)$ attended elementary school, and the remaining had secondary $(n=28$, $16.7 \%$ ) or higher education ( $n=14,8 \%$ ).

The date of surgery marked the onset of warfarin anticoagulation, and the results showed that the majority of the patients $(n=41)$ had undergone therapy for one year. The longest duration was five years $(n=14)$, followed by two-, three- and four-year durations in 35, 33 and 31 patients, respectively. The remaining 13 patients had been on anticoagulation for the last six months.

A total of 153 (91.9\%) participants confirmed receiving medical information. Only 6 of the patients (3.6\%) responded correctly to the type of surgery they had, and 168 patients (96.4\%) were unaware of the fact that they had a mechanical mitral valve replacement.

Among the participants requested to show warfarin among other prescriptions, only 25 patients (14.9\%) were unable to do so, and the majority ( $n=143,85.1 \%)$ recognised warfarin. 110 patients $(65.5 \%)$ knew the rationale for using warfarin, and the others $(n=58,34.5 \%)$ did not.

The majority of patients ( $n=117,69.6 \%$ ) knew the risks of incorrect warfarin dosage. Fifty-eight patients (34.1\%) adhered to the warfarin dosages as prescribed, and $88(51.8 \%)$ patients took random doses outside of the prescription. The remaining 24 patients (14.1\%) admitted to using warfarin irregularly.

The majority of patients ( $n=145,86.3 \%$ ) adhered to follow-up visits. A total of $134(79.8 \%)$ did not have INR knowledge. The majority ( $n=156,92.9 \%$ ) were unaware of the interactions between warfarin and food. Among the 21 patients (12.5\%) who stopped taking warfarin, $9(5 \%)$ did so following their doctor's recommendations.

The final section of the interview asked about warfarin-related complications, and the results revealed that 151 patients (89.9\%) did not have any complications. The leading types of complications were haemorrhagic cerebrovascular events ( $n$ $=5,3 \%)$ and gastrointestinal bleeding $(n=5,3 \%)$. Gingival bleeding, menorrhagia and haematuria were present in 6 patients (2 for each complication). Though not related to trauma, 1 patient experienced easy bruising. 10 patients who experienced some type of complication went to see a physician, and 4 patients stopped taking warfarin on their own. The remaining 3 patients did not take any action concerning their complications.

The statistical analyses revealed no relationship between complications and the medical information received by the patient ( $p=0.464)$. No relationship was found between complications and knowledge on the type of surgery $(p=0.522)$.

A statistically significant decrease in the frequency of complications was found in patients who were informed about the rationale of warfarin use $(p=0.028)$. The rate of complications in patients who adhered to follow-up visits was statistically lower than that of patients who did not adhere $(p=0.003)$. A significantly higher rate of complications was found in patients who stopped using warfarin without their doctor's recommendations $(p=0.001)$. Table 1 presents the rates of complications regarding warfarin anticoagulation therapy.

The statistical analysis revealed that patients who received medical information were aware of the rationale for warfarin use $(p=0.001)$, the risks of incorrect dosage $(p=0.028)$, the significance of follow-up visits $(p=0.001)$ and the rationale of INR $(p=0.028)$ (Table 2). 


\begin{tabular}{|c|c|c|c|}
\hline & \multicolumn{2}{|c|}{ Complications } & \multirow[t]{2}{*}{$p$} \\
\hline & Absent & Present & \\
\hline & $n(\%)$ & $n(\%)$ & \\
\hline $\begin{array}{l}\text { Recognition of warfarin } \\
\text { no } \\
\text { yes }\end{array}$ & $\begin{array}{l}23(15.2) \\
128(84.8)\end{array}$ & $\begin{array}{l}2(11.8) \\
15(88.2)\end{array}$ & 0.520 \\
\hline $\begin{array}{l}\text { Rationale for warfarin use } \\
\text { no } \\
\text { yes }\end{array}$ & $\begin{array}{l}48(31.8) \\
103(68.2)\end{array}$ & $\begin{array}{l}10 \text { (58.8) } \\
7(41.2) \\
\end{array}$ & $0.028 *$ \\
\hline $\begin{array}{l}\text { Knowledge of the risks of } \\
\text { incorrect warfarin dosage } \\
\text { no } \\
\text { yes }\end{array}$ & $\begin{array}{l}48(31.8) \\
103(68.2)\end{array}$ & $\begin{array}{l}3(17.6) \\
14(82.4)\end{array}$ & 0.179 \\
\hline $\begin{array}{l}\text { Adherence to prescription } \\
\text { adhered as recommended } \\
\text { non-adherence, took } \\
\text { random doses outside of } \\
\text { the prescription }\end{array}$ & $\begin{array}{l}49(32.5) \\
83(55.0) \\
\end{array}$ & $\begin{array}{l}9(52.9) \\
5(29.4)\end{array}$ & 0.131 \\
\hline $\begin{array}{l}\text { Adherence to follow-up visits } \\
\text { no } \\
\text { yes }\end{array}$ & $\begin{array}{l}16(10.6) \\
135(89.4)\end{array}$ & $\begin{array}{l}7(41.2) \\
10(58.8)\end{array}$ & $0.003^{*}$ \\
\hline $\begin{array}{l}\text { Knowledge of INR } \\
\text { no } \\
\text { yes }\end{array}$ & $\begin{array}{l}119(78.8) \\
32(21.2)\end{array}$ & $\begin{array}{l}15(88.2) \\
2(11.8)\end{array}$ & 0.287 \\
\hline $\begin{array}{l}\text { Knowledge of interactions of } \\
\text { warfarin with foods } \\
\text { no } \\
\text { yes }\end{array}$ & $\begin{array}{l}139(92.1) \\
12(7.9)\end{array}$ & $\begin{array}{l}17(100.0) \\
0(0.0)\end{array}$ & 0.265 \\
\hline $\begin{array}{l}\text { Stopped using warfarin } \\
\text { no } \\
\text { yes, doctor's recommenda- } \\
\text { tion } \\
\text { yes }\end{array}$ & $\begin{array}{l}135(89.4) \\
5(3.3) \\
11(7.3)\end{array}$ & $\begin{array}{l}3(17.6) \\
4(23.5) \\
10(58.8)\end{array}$ & $0.001 *$ \\
\hline
\end{tabular}

${ }^{*}$ A $p$-value $<0.05$ is statistically significant.

\begin{tabular}{|c|c|c|c|}
\hline & \multicolumn{2}{|c|}{$\begin{array}{l}\text { Medical information } \\
\text { provided }\end{array}$} & \multirow[t]{2}{*}{$p$} \\
\hline & No & Yes & \\
\hline $\begin{array}{l}\text { Recognition of warfarin } \\
\text { no } \\
\text { yes }\end{array}$ & $\begin{array}{l}0(0.0) \\
15(100.0)\end{array}$ & $\begin{array}{l}25(16.3) \\
128(83.7)\end{array}$ & 0.079 \\
\hline $\begin{array}{l}\text { Rationale for warfarin use } \\
\text { no } \\
\text { yes }\end{array}$ & $\begin{array}{l}15(100.0) \\
0(0.0)\end{array}$ & $\begin{array}{l}43(28.1) \\
110(71.9)\end{array}$ & $0.001 *$ \\
\hline $\begin{array}{l}\text { Knowledge of risks of incor- } \\
\text { rect warfarin dosage } \\
\text { no } \\
\text { yes }\end{array}$ & \begin{tabular}{|l}
$1(6.7)$ \\
$14(93.3)$
\end{tabular} & $\begin{array}{l}50(32.7) \\
103(67.3)\end{array}$ & $0.028 *$ \\
\hline $\begin{array}{l}\text { Adherence to prescription } \\
\text { adhered as recommended } \\
\text { non-adherence, took } \\
\text { random doses outside of } \\
\text { the prescription } \\
\text { irregular use }\end{array}$ & $\begin{array}{l}13(86.7) \\
0(0.0) \\
2(13.3)\end{array}$ & $\begin{array}{l}45(29.4) \\
88(57.5) \\
20(13.1)\end{array}$ & $0.001 *$ \\
\hline $\begin{array}{l}\text { Adherence to follow-up visits } \\
\text { no } \\
\text { yes }\end{array}$ & $\begin{array}{l}12(80.0) \\
3(20.0)\end{array}$ & $\begin{array}{l}11(7.2) \\
142(92.8)\end{array}$ & $0.001^{*}$ \\
\hline $\begin{array}{l}\text { Knowledge of INR } \\
\text { no } \\
\text { yes }\end{array}$ & $\begin{array}{l}15(100.0) \\
0(0.0)\end{array}$ & $\begin{array}{l}119(77.8) \\
34(22.2)\end{array}$ & $0.028 *$ \\
\hline
\end{tabular}

\begin{tabular}{|l|l|l|l|}
\hline $\begin{array}{l}\text { Knowledge of interactions of } \\
\text { warfarin with foods } \\
\text { no } \\
\text { yes }\end{array}$ & $\begin{array}{l}15(100.0) \\
0(0.0)\end{array}$ & $\begin{array}{l}141(92.2) \\
12(7.8)\end{array}$ & 0.313 \\
\hline $\begin{array}{l}\text { Stopped using warfarin } \\
\text { no }\end{array}$ & $12(80.0)$ & $126(82.4)$ & \\
$\begin{array}{l}\text { yes, doctor's recommenda- } \\
\text { tion }\end{array}$ & $0(0.0)$ & $9(5.9)$ & \\
yes & $3(20.0)$ & $18(11.8)$ & 0.442 \\
\hline
\end{tabular}

${ }^{*}$ A $p$-value $<0.05$ is statistically significant.

\section{Discussion}

This study was undertaken to obtain the current understanding of the knowledge profile of patients who were on warfarin anticoagulation therapy due to mechanical mitral valve replacement surgery and to evaluate the consequences of patients' knowledge about anticoagulation therapy. The success and safety of anticoagulation therapy are directly affected by the anticoagulant, the dosage, the physician's experience, compliance and adherence, close monitoring, follow-up visits and the education provided to the patient. Among these factors, patient education is considered a key factor for safe and optimal anticoagulation therapy $[8,9,14]$. Literature is rich with research on the adherence, satisfaction and outcome of patients on anticoagulation therapy [4, 9]. Most investigations have been performed on a range of patients on anticoagulants but have not focused on the mechanical heart valve [15]. A clear conclusion is difficult to reach when a single study investigates multiple variables, such as numerous indications [16-18] and anticoagulants [14]. For clarity, we designed our study to focus on a single group of patients on a single anticoagulant. Here, we investigated the knowledge profiles of patients who had mechanical mitral valve replacement and who were on warfarin anticoagulation therapy and identified the relationship between anticoagulation and complications.

The age of the patients in this study ranged from 18 to 83, with a mean value of $61.76 \pm 9.35$ years, and females $(n=89)$ outnumbered males $(n=79)$. Only one-quarter of the patients attended middle and high school, and the majority (75\%) graduated from elementary school. The duration of warfarin anticoagulation therapy was between 6 months and 5 years, and the majority $(n=139)$ had been on warfarin for $1-4$ years.

In a study on patients with a mean age of $60.42 \pm 13.4$, knowledge about warfarin was found to be poorer in the elderly [19]. A similar association between older age (mean $=47.9 \pm 13.9$ and $60 \pm 14.6$ years) and poor knowledge was found in two other studies $[11,14]$. An age older than 61 years was found to be a significant factor in determining patient knowledge [20]. In all the studies reviewed, the older age groups significantly lacked knowledge about most facets of anticoagulation therapy $[9,12,13$, $16-18,21,22]$. The mean age in these studies was similar to ours; thus, poor knowledge about warfarin anticoagulation in the current study is consistent with literature. As previously suggested [19], we assumed that the level of knowledge in the elderly was poor due to a decline in cognitive skills. Additionally, it is possible that relevant education was given to the caregivers.

We did not notice any consensus among the studies on the association between gender and warfarin anticoagulation knowledge. Nevertheless, a relationship between gender in predominantly female populations and poor anticoagulation knowledge was found $[13,17,21]$. As our study group mostly consisted of female patients, the poor knowledge level we observed was consistent with previous literature. The relationship between education and anticoagulation knowledge has been extensively researched. As demonstrated by our results, a lower level of education seems to be linked to poor anticoagulation knowledge. Although there is conclusive research in favour of 
this plausible relationship $[12,14,19]$, there are other studies with contradictory results, i.e. no significant association between education and knowledge of anticoagulants [13, 17, 23]. For example, in a study in which the median education was at least middle school, the rate of insufficient warfarin knowledge was as high as $61 \%$ [24]. We suspect that the inconsistency in the relationship between education and anticoagulation knowledge may be due to the methodological variations or the variables investigated in such studies.

A total of $91.1 \%$ of the participants received medical information. Interestingly, only 6 patients (3.6\%) had knowledge of the type of surgery they had. This rate is significantly lower than the frequency of patients $(96.6 \%)$ who claimed to know the indication of warfarin therapy in another study [22]. The number of patients who recognised warfarin among other prescriptions was $25(14.9 \%)$, which was much lower than that in another study (90\%) [24]. Among the patients, $65.5 \%$ knew the rationale of warfarin use. Compared with lower rates in other studies [4, $14]$, this result suggests sufficient and informative relevant medical education provided to our patients. The majority (69.6\%), which is higher than reported rates of $18 \%$ [24], 29.7\% [14], 42.8 [22] and $42 \%$ [18], were aware of the risks of incorrect warfarin dosage, suggesting that our patients had a good level of knowledge about the relevant risks of incorrect warfarin dosage.

The adherence rate to warfarin prescription in our study was $34.1 \%$, which was lower than the rate $(93.1 \%)$ reported by Joshua and Kakkar [14]. Moreover, $86.3 \%$ of our patients adhered to follow-up visits, and this is consistent with the rate $(85.1 \%)$ reported in another study [14]. Higher rates of adherence to prescription timing $(94.8 \%)$ and dose $(93.5 \%)$ of warfarin and regular examinations $(90.8 \%)$ were reported in a recent study [13]. Similar to the results of Wang et al., higher rates of compliance (88-94.5\%) to warfarin prescriptions were found in two other studies [13]. As reported previously, knowledge was directly associated with adherence [9]. Thus, it is not surprising to obtain lower adherence rates in our study, which showed poor levels of patient knowledge.

Most of the patients $(92.9 \%)$ in our study were unaware of food interactions with warfarin, a result consistent with other studies $[11,12,18,22,24]$. As previously suggested, this may indicate insufficient information on dietary considerations provided to the patient $[18,22]$.

The significance of INR knowledge as a principal predictor of warfarin knowledge was emphasised by several researchers $[9,16,20,22]$. Although physicians frequently use INR during anticoagulation, physicians were likely to assume that this was comprehendible to the patients. This misconception is present in our study, as $79.8 \%$ of the patients did not know about INR, thus supporting other studies $(75-76 \%)[18,22]$.

Studies have indicated poor knowledge about warfarin among patients who received medical information [16]. When we collectively considered the responses to the first three sections of the questionnaire, we noticed a discrepancy: although the rate of participants who reported that they received medical information (91.1\%) was very high, the knowledge level on the remaining items in these domains was relatively deficient. This difference may be due to social desirability, a recall bias or a lack of awareness on the lack of knowledge, which, in our opinion, is the most dangerous option of all.

The frequency of complications in our study was $10.1 \%$, and the leading incidents were haemorrhagic cerebrovascular events and gastrointestinal bleeding. Moran et al. reported a rate of $20 \%$ and haemorrhage as the most common (37.1\%) complication [22]. In another study, the complication rate was more than twice that of our rate $(27 \%)$, and one-third of the incidents were gastrointestinal events [18]. Sonuga et al. reported a frequency of $14 \%$ for haemorrhagic events [25]. Moreover, $58.5 \%$ of the patients who had complications went to see a physician, and $23.5 \%$ of them stopped taking warfarin. Taken together, $82 \%$ of the patients who developed complications knew the appropriate actions to be taken. This result is consistent with the rate from similar studies (66.9-95.5\%) [9, 14, 18, 22].

In this study, we did not observe any relationship between complications and the medical knowledge of patients $(p=0.464)$ or between complications and the knowledge about the type of surgery $(p=0.522)$. We found a significant decrease in complication rates in patients who were informed about the rationale of warfarin $(p=0.028)$ and who adhered to follow-up visits ( $p=$ 0.003 ). A higher risk of complications was demonstrated in patients who did not adhere to warfarin prescriptions $(p=0.001)$. The statistical analysis revealed that patients who received medical information were aware of the rationale for warfarin use $(p=0.001)$, the risks of incorrect dosage $(p=0.028)$, the significance of follow-up visits $(p=0.001)$ and the rationale of INR $(p=0.028)$ (Table 2). Most of the studies we reviewed presented a total score for anticoagulation knowledge but did not provide detailed information on the subdomains. Therefore, it seems irrelevant to compare the current results with such data obtained using a different methodology, various patient education methods and different sources of patient recruitment [15]. Nevertheless, we can safely conclude that our results showed a poor level of knowledge on warfarin anticoagulation in patients who were not given sufficient and appropriate medical information. Moreover, we found that providing medical information had a significant positive effect on adherence while decreasing the frequency of complications related to warfarin anticoagulation.

This study has its limitations and strengths. The descriptive and retrospective nature of the study design, the use of a selfdeveloped questionnaire that lacks validation and internal consistency studies and a one-time assessment that is prone to recall bias can be considered limitations of this research. Conversely, the strengths of this study include the moderate size of the study population, the recruitment of participants from multiple hospitals covering a wide region, thus enforcing the generalisability of the results, a study protocol with face-to-face interviews and research focused on a single type of indication for anticoagulation (mechanical mitral valve replacement surgery) and a single type of anticoagulant (warfarin).

\section{Conclusions}

In conclusion, regardless of the reason that led to the poor level of knowledge in our study population, we found a considerable gap between the ideal conditions and the current status. We tend to view these results from an optimistic perspective and suggest that this study should serve as a first step towards identifying the domains of knowledge that require more and immediate improvement. The significant associations found between the provided medical information on warfarin and the lower complication rates are promising and can pave the way for larger and more focused research studies that can ultimately lead to standardised educational tools for patient education on anticoagulation.

Source of funding: This work was funded from the authors' own resources.

Conflicts of interest: The authors declare no conflicts of interest.

\section{References}

1. Nkomo VT, Gardin JM, Skelton TN, et al. Burden of valvular heart diseases: a population-based study. Lancet 2006; 368(9540): 1005-1011, doi: 10.1016/s0140-6736(06)69208-8. 
2. Maclsaac S, Jaffer IH, Belley-Cote EP, et al. How did we get here? A historical review and critical analysis of anticoagulation therapy following mechanical valve replacement. Circulation 2019; 140(23): 1933-1942, doi: 10.1161/circulationaha.119.041105.

3. Riva N, Borg Xuereb C, Ageno W, et al. Validation and psychometric properties of the Maltese version of the Duke Anticoagulation Satisfaction Scale (DASS). Psychol Res Behav Manag 2019; 12: 741-752, doi: 10.2147/prbm.S216617.

4. Souza TF de, Colet CF, Heineck I. Knowledge and information levels and adherence to oral anticoagulant therapy with warfarin in patients attending primary health care services. J Vasc Bras 2018; 17(2): 109-116, doi: 10.1590/1677-5449.012017.

5. Nishimura RA, Otto CM, Bonow RO, et al. 2017 AHA/ACC focused update of the 2014 AHA/ACC guideline for the management of patients with valvular heart disease: a report of the American College of Cardiology/American Heart Association Task Force on Clinical Practice Guidelines. Circulation 2017; 135(25): e1159-e1195, doi: 10.1161/cir.0000000000000503.

6. Hirsh J. Oral anticoagulant drugs. N Engl J Med 1991; 324(26): 1865-1875, doi: 10.1056/nejm199106273242606.

7. Witt DM, Nieuwlaat R, Clark NP, et al. American Society of Hematology 2018 guidelines for management of venous thromboembolism: optimal management of anticoagulation therapy. Blood Adv 2018; 2(22): 3257-3291, doi: 10.1182/bloodadvances.2018024893.

8. Balkhi B, Al-Rasheedi M, Elbur Al, et al. Association between satisfaction with and adherence to warfarin therapy on the control of international normalized ratio: a hospital-based study in Saudi Arabia. Saudi Pharm J 2018; 26(1): 145-149, doi: 10.1016/j.jsps.2017.11.010.

9. Yiu A, Bajorek B. Patient-focused interventions to support vulnerable people using oral anticoagulants: a narrative review. Ther Adv Drug Saf 2019; 10: 2042098619847423, doi: 10.1177/2042098619847423.

10. Silva Praxedes MF da, Sousa Vianna M, Freitas Nunes Sousa WJ de, et al. Instruments for the assessment of patient adherence to oral anticoagulation with warfarin protocol for a systematic review. Medicine (Baltimore) 2019; 98(42): e17323, doi: 10.1097/ md.0000000000017323.

11. Shrestha S, Sapkota B, Kumpakha A, et al. Evaluation of patients' knowledge on warfarin in outpatient pharmacy of a tertiary care cardiac center. BMC Res Notes 2015; 8: 429, doi: 10.1186/s13104-015-1416-1.

12. Viola R, Fekete H, Csoka I. Patients' knowledge on oral anticoagulant treatment in Hungary. Int J Clin Pharm 2017; 39(6): 1265-1272, doi: 10.1007/s11096-017-0544-1.

13. Wang $\mathrm{X}, \mathrm{Xu} \mathrm{B}$, Liang $\mathrm{H}$, et al. Distribution characteristics and factors influencing oral warfarin adherence in patients after heart valve replacement. Patient Prefer Adherence 2018; 12: 1641-1648, doi: 10.2147/ppa.S172223.

14. Joshua JK, Kakkar N. Lacunae in patient knowledge about oral anticoagulant treatment: results of a questionnaire survey. Indian J Hematol Blood Transfus 2015; 31(2): 275-280, doi: 10.1007/s12288-014-0415-z.

15. Damme S van, Deyk K van, Budts W, et al. Patient knowledge of and adherence to oral anticoagulation therapy after mechanical heartvalve replacement for congenital or acquired valve defects. Heart Lung 2011; 40(2): 139-146, doi: 10.1016/j.hrtlng.2009.11.005.

16. Hu A, Chow CM, Dao D, et al. Factors influencing patient knowledge of warfarin therapy after mechanical heart valve replacement. J Cardiovasc Nurs 2006; 21(3): 169-175; quiz 76-77, doi: 10.1097/00005082-200605000-00003.

17. Shilbayeh SAR, Almutairi WA, Alyahya SA, et al. Validation of knowledge and adherence assessment tools among patients on warfarin therapy in a Saudi hospital anticoagulant clinic. Int J Clin Pharm 2018; 40(1): 56-66, doi: 10.1007/s11096-017-0569-5.

18. Shuaib W, Iftikhar H, Alweis R, et al. Warfarin therapy: survey of patients' knowledge of their drug regimen. Malays J Med Sci 2014; 21(4): 37-41.

19. Hasan SS, Shamala R, Syed IA, et al. Factors affecting warfarin-related knowledge and INR control of patients attending physician- and pharmacist-managed anticoagulation clinics. J Pharm Pract 2011; 24(5): 485-493, doi: 10.1177/0897190011415684.

20. Nadar S, Begum N, Kaur B, et al. Patients' understanding of anticoagulant therapy in a multiethnic population. J R Soc Med 2003; 96(4): 175-179, doi: 10.1258/jrsm.96.4.175.

21. Li X, Sun S, Wang Q, et al. Assessment of patients' warfarin knowledge and anticoagulation control at a joint physician- and pharmacistmanaged clinic in China. Patient Prefer Adherence 2018; 12: 783-791, doi: 10.2147/ppa.S156734.

22. Moran SM, Fitzgerald N, Pope M, et al. Warfarin anticoagulation: a survey of patients' knowledge of their treatment. Ir J Med Sci 2011; 180(4): 819-822, doi: 10.1007/s11845-011-0726-0.

23. Baysal E, Midilli TS. Effects of structured patient education on knowledge level and INR control of patients receiving warfarin: randomized controlled trial. Pak J Med Sci 2018; 34(2): 240-246, doi: 10.12669/pjms.342.14216.

24. Wilson FL, Racine E, Tekieli V, et al. Literacy, readability and cultural barriers: critical factors to consider when educating older African Americans about anticoagulation therapy. J Clin Nurs 2003; 12(2): 275-282, doi: 10.1046/j.1365-2702.2003.00711.x.

25. Sonuga BO, Hellenberg DA, Cupido CS, et al. Profile and anticoagulation outcomes of patients on warfarin therapy in an urban hospital in Cape Town, South Africa. Afr J Prim Health Care Fam Med 2016; 8(1): e1-e8, doi: 10.4102/phcfm.v8i1.1032.

Tables: 2

Figures: 0

References: 25

Received: 19.08 .2020

Reviewed: 10.09 .2020

Accepted: 4.11.2020

Address for correspondence:

ilker Kaya, MD

Department of Cardiovascular Surgery

Tokat State Hospital

60100 Tokat

Turkey

Tel.: +90 5332258435

E-mail: kayalker60@gmail.com 